ISSN 2525-5215

DOI: $10.48017 /$ dj.v6i4.1946

Volume 6, Número 4 (out./dez. 2021 ) pp: 3866-3881. https://periodicos.ifal.edu.br/diversitas_journal/ (C) Diversitas Journal

\title{
Actinobactérias com potencial biotecnológico agrícola isoladas de adubo orgânico fermentado (Bokashi)
}

\section{Actinobacteria with agricultural biotechnological potential isolated from fermented organic fertilizer (Bokashi)}

\author{
Leonardo da Silva Santos ${ }^{(1)}$; Giselle Silva de Souza ${ }^{(2)}$; Luana Gomes da Silva ${ }^{(3)}$; \\ Lyslem Riquelem de Araújo ${ }^{(4)}$; Mirca Melo Rodrigues da Silva ${ }^{(5)}$; Esmeralda \\ Aparecida Porto Lopes ${ }^{(6)}$
}

\begin{abstract}
(1) ORCID: O000-0003-2617-436X; Graduando de Licenciatura em Ciências Biológicas; Universidade Estadual de Alagoas - UNEAL; Brazil; Bolsista PIBIT pela Fundação de Amparo à Pesquisa do Estado de Alagoas - FAPEAL; E-mail: leossantos.bio@gmail.com; (2) ORCID: OOO0-0003-2598-4205; Graduanda de Licenciatura em Ciências Biológicas; UNEAL; Brazil; Bolsista PIBIT pela Fundação de Amparo à Pesquisa do Estado de Alagoas - FAPEAL; E-mail: giselle.silva908@gmail.com;

(s) ORCID: 0000-0002-7140-581X; Graduanda de Licenciatura em Ciências Biológicas; UNEAL; Brazil; E-mail: luanag.ds.96@gmail.com;

(4) ORCID: OOOO-0002-1550-3482; Graduanda de Licenciatura em Ciências Biológicas; UNEAL; Brazil; E-mail: araujolyslem23@gmail.com;

(5) ORCID: OOOO-0002-6714-1495; Graduanda de Licenciatura em Ciências Biológicas; UNEAL; Brazil; E-mail: mircam55@gmail.com;

(6) ORCID: OOOO-0003-3765-0712; Professora do Departamento de Ciências Biológicas da Universidade Estadual de Alagoas UNEAL/Campus I; Brazil; E-mail: esmeralda.porto@uneal.edu.br
\end{abstract}

Todo o conteúdo expresso neste artigo é de inteira responsabilidade dos seus autores.

Recebido em: 05 de julho de 2020; Aceito em: 10 de setembro de 2021; publicado em 10 de outubro de 2021. Copyright (C) Autor, 2021.

RESUMO: O Bokashi é um tipo de fermentado orgânico formado por fungos e bactérias isolados de matas e que coexistem sinergicamente em meio líquido fermentativo. Dentre esses microrganismos, algumas espécies de actinobactérias apresentam potencial biotecnológico aplicado na produção de produtos naturais úteis para a agricultura. Neste sentido, o presente trabalho teve como objetivo isolar e identificar actinobactérias com potencial biotecnológico agrícola presentes em adubo orgânico fermentado (Bokashi). O Bokashi foi produzido através da captura de microrganismos presentes no solo de mata. As actinobactérias foram isoladas através de diluições sucessivas de amostras do Bokashi e crescidas nos meios de cultura Czapeck Modificado (MC), Arginina Vitamina Ágar (AY*), Inorganic Salt - starch Ágar (ISP-4) contendo antifúngico e incubadas a $30{ }^{\circ} \mathrm{C}$ por 21 dias. A análise micromofológica e identificação foi realizada através da técnica de microcultivo em lâminas. Ao todo, foram isoladas e identificadas 22 cepas de actinobactérias, das quais 77,27\% foram provenientes do meio AY*; $13,64 \%$ do meio ISP-4 e 9,09\% do meio MC. A identificação presuntiva dos gêneros mostrou que as cepas estavam distribuídas entre: 45,45\% Nocardia; 36,36\% Streptomyces; 9,10\% Terrabacter; 4,54\% Micromonospora; e 4,54\% Mycobacterium.

PALAVRAS-CHAVE: Microrganismos Eficazes, Agricultura sustentável, Biotecnologia.

ABSTRACT: Bokashi is a type of organic ferment formed by fungi and bacteria isolated from forests and which coexist synergistically in a liquid fermentative medium. Among these microorganisms, some species of actinobacteria have biotechnological potential applied in the production of natural products useful for agriculture. In thus sense, the present work aimed to isolate and identify actinobacteria with agricultural biotechnological potential present in fermented organic fertilizer (Bokashi). Bokashi was produced by capturing microorganisms present in the forest soil. Actinobacteria were isolated through successive dilutions of Bokashi samples and grown in culture media Czapeck Modified (MC), Arginine Vitamin Agar (AY*), Inorganic Salt - starch Agar (ISP-4) containing antifungal and incubated at $30{ }^{\circ} \mathrm{C}$ for 21 days. Micromorphological analysis and identification was performed using the microculture on slides technique. In all, 22 strains of actinobacteria were isolated and identified, of which $77.27 \%$ were from the $\mathrm{AY}^{*}$ medium; $13.64 \%$ of ISP-4 medium and $9.09 \%$ of MC medium. The presumptive identification of the genders showed that the strains were distributed between: $45.45 \%$ Nocardia; $36.36 \%$ Streptomyces; $9.10 \%$ Terrabacter; 4.54\% Micromonospora; and 4.54\% Mycobacterium.

KEYWORDS: Effective Microorganisms, Sustainable Agriculture, Biotechnology. 


\section{INTRODUÇÃO}

O Brasil abriga grande diversidade microbiana e ainda há microrganismos a serem estudados por causa da capacidade de produzirem metabólitos que podem contribuir na fabricação de produtos naturais úteis na agricultura. Assim, estudos têm buscado aumentar a produtividade das culturas com a utilização de bioinoculantes (KUMAR; GOPAL, 2015) os quais, na sua maioria, são produzidos com estirpes microbianas fermentadas ou cultivadas separadamente gerando o produto final com inóculos puros (CALVO; NELSON; KLOEPPER, 2014).

Um dos processos de fermentação controlada, em que ocorre a mistura balanceada de materiais orgânicos de origem vegetal e/ou animal, é a técnica do Bokashi, que foi trazida do Japão e adaptada pelos agricultores brasileiros no final da década de 80. Para a fabricação do Bokashi, além da matéria orgânica balanceada, há a necessidade do uso de fermentos biológicos que podem ser feitos a partir de sua captura em solos de matas, através de outros fermentos conhecidos para produção de alimentos fermentados ou, ainda, por produtos comerciais conhecidos como aceleradores de compostagem (SIQUEIRA; SIQUEIRA, 2013).

Entre os diversos tipos de fermentos ou microrganismos que fazem o tipo de fermentação adequado para a produção do Bokashi, merece destaque a categoria denominada Microrganismos Eficazes (EM), formada por fungos e bactérias isolados de matas e que coexistem sinergicamente em meio líquido fermentativo enriquecido com fonte de açúcar (BONFIM et al., 2011).

Alguns desses microrganismos são conhecidos há milhares de anos e utilizados na fermentação e conservação dos alimentos. Entre estes, as actinobactérias produzem metabólitos secundários que podem influenciar no desenvolvimento de plantas e na produção de hormônios que atuam na secreção de antibióticos e toxinas controlando patógenos (VASCONCELLOS et al., 2010), sendo empregados no biocontrole, ou seja, são utilizados para reduzir a intensidade das fitodoenças provocadas nas plantas por outros organismos, como fungos fitopatogênicos (PINTO et al., 2010; TEIXEIRA et al., 2013).

Sendo os agrotóxicos utilizados com frequência nos sistemas de produção, causando diversos impactos ambientais e sociais (OCTAVIANO, 2010), isolar 
SANTOS, Leonardo da Silva; SOUZA, Giselle Silva de; SILVA, Luana Gomes da; ARAúJO, Lyslem Riquelem de; SILVA, Mirca Melo Rodrigues da; LOPES, Esmeralda Aparecida Porto

microrganismos com potencial biotecnológico agrícola torna-se necessário principalmente para a realização de novas pesquisas que testem seus respectivos potenciais a serem aplicados na fabricação de produtos naturais que possam contribuir para um manejo agrícola mais sustentável. Dessa forma, objetivou-se neste trabalho isolar e identificar actinobactérias com potencial biotecnológico agrícola presentes em adubo orgânico fermentado (Bokashi).

\section{PROCEDIMENTO METODOLÓGICO}

\section{Local da captura e isolamento dos EM para a produção do Bokashi e condução do isolamento das actinobactérias}

A captura dos EM para a produção do Bokashi ocorreu em uma mata da Reserva Particular do Patrimônio Natural (RPPN) Madeiras, localizada no município de Junqueiro - AL. A reserva é um fragmento de vegetação secundária de mata atlântica com área de 124,52 ha, em terreno acidentado (IMA, 2015). O município de Junqueiro está localizado na região centro-sul do Estado de Alagoas, limitando-se a norte com os municípios de Limoeiro de Anadia e Campo Alegre, a sul com Teotônio Vilela e São Sebastião, a leste com Campo Alegre e Teotônio Vilela, e a oeste com Arapiraca, Limoeiro de Anadia e São Sebastião (CPRM, 2005). Assim, Junqueiro está inserido na Zona da Mata Alagoana ( $9^{\circ} 53^{\prime} \mathrm{O} 2^{\prime \prime}$ e $\left.36^{\circ} 28^{\prime} 25^{\prime \prime}\right)$, com clima do tipo Tropical Chuvoso e verão seco. O período chuvoso começa no outono tendo início em fevereiro e término em outubro. A precipitação média anual é de $1.634 .2 \mathrm{~mm}$ e possui temperatura máxima de $35^{\circ} \mathrm{C}$ e mínima de $22^{\circ} \mathrm{C}$ (IBGE, 2017).

A captura dos microrganismos ocorreu no período que corresponde ao verão da região, a partir do cozimento de $700 \mathrm{~g}$ de arroz sem sal. Estes foram colocados em bandejas e cobertos por uma fina tela de proteção, sendo depositadas no solo e cobertas com uma camada de serapilheira por 10 dias. Após esse período, os grãos foram coletados e selecionados conforme a metodologia descrita por Bonfim et al. (2011).

$\mathrm{O}$ isolamento dos EM, assim como a purificação e identificação das actinobactérias presentes no Bokashi foram conduzidas no Laboratório de Análises Microbiológicas do Polo Tecnológico Agroalimentar de Arapiraca, localizado no 
SANTOS, Leonardo da Silva; SOUZA, Giselle Silva de; SILVA, Luana Gomes da; ARAÚJO, Lyslem Riquelem de; SILVA, Mirca Melo Rodrigues da; LOPES, Esmeralda Aparecida Porto

Povoado Bananeira, pertencente ao município de Arapiraca - Alagoas. Os EM foram isolados de ambiente autóctone e, em seguida, foram crescidos em um meio nutritivo com sacarose e água destilada em garrafa pet de 2 litros e mantidos a uma temperatura de $60^{\circ} \mathrm{C}$ por 20 minutos. Logo após, foi hermeticamente fechado, mantido por mais 10 dias a uma temperatura de $30^{\circ} \mathrm{C}$, sendo aberto no quinto dia para a liberação de gases produzidos pelo processo de fermentação.

\section{Isolamento e quantificação das actinobactérias}

As actinobactérias foram isoladas através de diluições sucessivas (tampão PBS $0,85 \%)$ de amostras do Bokashi até $10^{-5}$. Foram utilizadas as três últimas diluições $\left(10^{-3}\right.$, $10^{-4}$ e $\left.10^{-5}\right)$, sendo delas transferidos $0,1 \mathrm{~mL}$ do sobrenadante nos meios de cultura Czapeck Modificado (MC), Arginina Vitamina Ágar (AY*), Inorganic Salt - starch Ágar (ISP-4), com $80 \mu \mathrm{g} / \mathrm{mL}$ de antifúngico contendo cimoxanil + famoxadona. As placas foram incubadas a $30{ }^{\circ} \mathrm{C}$ por até 21 dias em estufa bacteriológica. $\mathrm{O}$ experimento foi realizado em triplicatas (Figura 1).

Figura 1: Esquema de diluição seriada do Bokashi e inoculação.

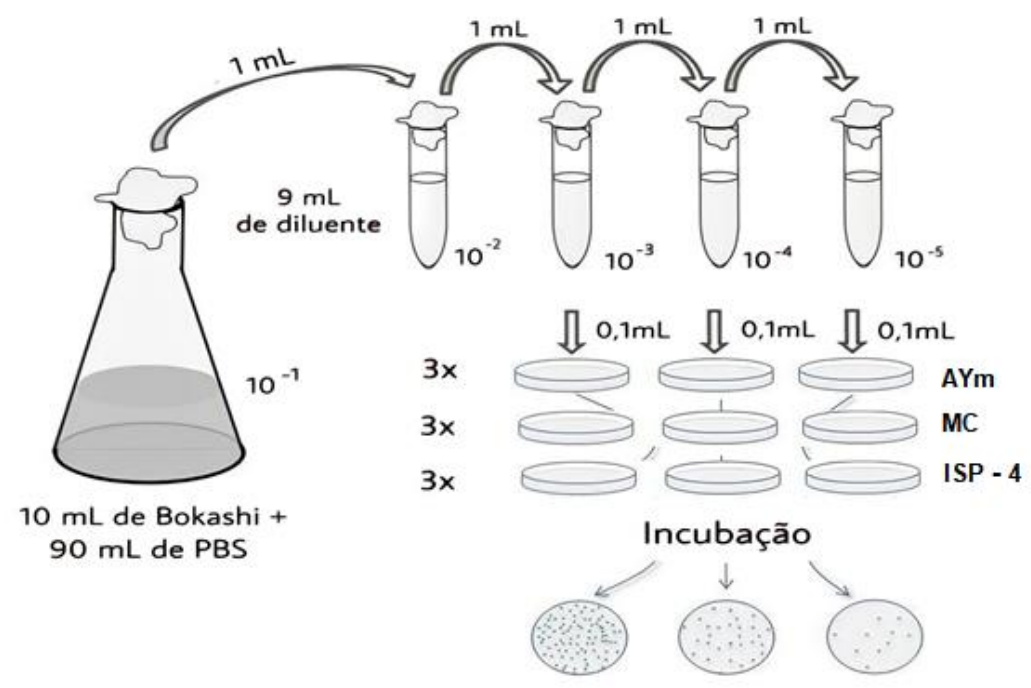

Fonte: Acervo dos autores (2021). 
SANTOS, Leonardo da Silva; SOUZA, Giselle Silva de; SILVA, Luana Gomes da; ARAÚJO, Lyslem Riquelem de; SILVA, Mirca Melo Rodrigues da; LOPES, Esmeralda Aparecida Porto

Para a quantificação das linhagens obtidas no isolamento foi realizada a contagem de unidades formadoras de colônias (UFC), sendo consideradas as placas que apresentaram quantificação entre 30 a 300 e, em seguida, sendo transferidas para novas placas de Petri contendo os meios citados anteriormente.

\section{Análise micromorfológica}

Para análise micromorfológica das actinobactérias, foi utilizada a técnica de microcultivo em lâminas descrita por Serrano e Sandoval (1992). Assim, os microrganismos foram cultivados nas extremidades de blocos quadrados de aproximadamente $1 \mathrm{~cm}^{3}$ dos meios MC, AY* e ISP-4 sob lâmina em placas de Petri com a inserção de lamínulas em cima dos meios de cultura contendo os microrganismos transferidos para crescimento das hifas sobre sua superfície. As placas foram incubadas a uma temperatura de $30^{\circ} \mathrm{C}$ por 21 dias em estufa bacteriológica (Figura 2).

Figura 2: Esquema do microcultivo das actinobactérias.

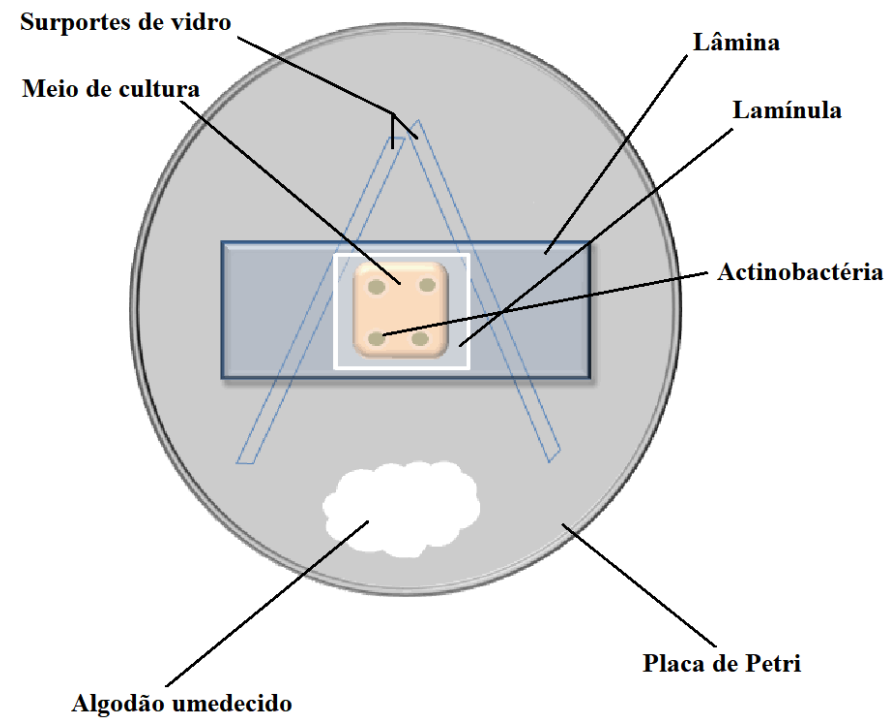

Fonte: Adaptado de Franco (2012). 
SANTOS, Leonardo da Silva; SOUZA, Giselle Silva de; SILVA, Luana Gomes da; ARAÚJO, Lyslem Riquelem de; SILVA, Mirca Melo Rodrigues da; LOPES, Esmeralda Aparecida Porto

Após o período de incubação, foram observadas características micromorfológicas como presença ou ausência de esporos, forma da cadeia de esporos ou a presença de esporângio, através de microscópio óptico com o aumento de 400X. Para confirmar a pureza de algumas linhagens isoladas, foram preparadas lâminas através da técnica de coloração de Gram e, em seguida, observadas em microscópio óptico com o aumento de 1000X para verificar se os microrganismos eram Gram-positivos ou Gram-negativos e ainda caracterizar sua micromorfologia, tal como se apresentavam forma filamentosa ou se fragmentavam em bacilos, cocos ou cocobacilos. A identificação dos gêneros foi realizada através da descrição presente no Bergey's Manual of Systematic Bacteriology (WILLAMS et al., 1989).

\section{RESULTADOS E DISCUSSÃO}

Ao todo, foram isoladas 22 cepas de actinobactérias do adubo orgânico fermentado (Bokashi), das quais 77,27\% (17) foram provenientes do meio AY; 13,64\% (3) do meio ISP-4 e 9,09\% (2) do meio MC (Figura 3). Porém, entre as diluições, a $10^{-5}$ no meio $\mathrm{AY}^{*}$ favoreceu o número maior de crescimento de cepas (45\%), enquanto no meio ISP-4 essa mesma diluição não obteve crescimento, havendo um maior número na $10^{-3}$ $(9,1 \%)$. Já no meio MC houve crescimento em todas as diluições, destacando-se a $10^{-3} \mathrm{e}$ $10^{-4}(9,1 \%$ cada). Isso se deve, provavelmente, às diferenças nutricionais encontradas em cada meio de cultura e nas concentrações das diluições utilizadas, pois, de acordo com Albuquerque et al. (2000), a escolha de diferentes meios de cultura é um pré-requisito para o isolamento de qualquer microrganismo. Assim, a utilização de diferentes meios de cultura no isolamento de actinobactérias, pode indicar uma relevante diversidade em diferentes ambientes.

Figura 3: Percentual de cepas de actinobactérias por meio de cultura. 
SANTOS, Leonardo da Silva; SOUZA, Giselle Silva de; SILVA, Luana Gomes da; ARAÚJO, Lyslem Riquelem de; SILVA, Mirca Melo Rodrigues da; LOPES, Esmeralda Aparecida Porto

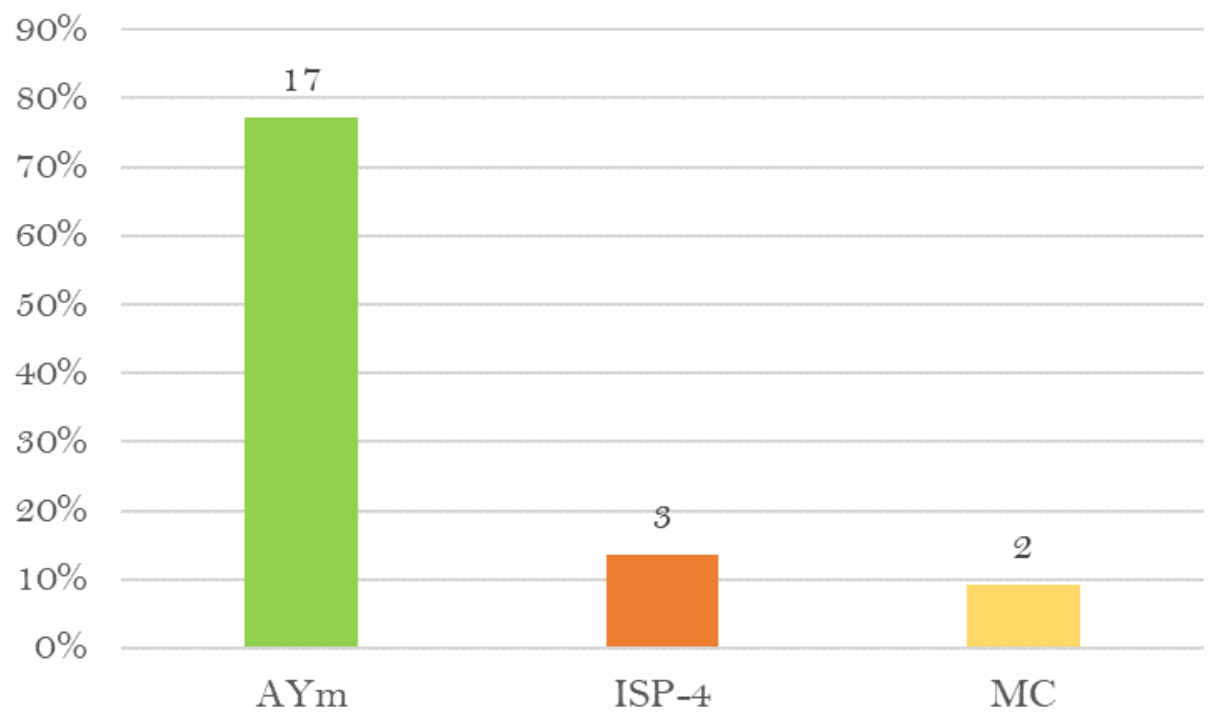

Fonte: Dados da pesquisa (2021).

Quanto a contagem de Unidades Formadoras de Colônias, o meio MC apresentou uma contagem média de $1,5 \times 10^{5} \mathrm{UFC} / \mathrm{ml}$, já o meio $\mathrm{AY}^{*}$ obteve 2,5 x $10^{5}$ $\mathrm{UFC} / \mathrm{ml}$, enquanto o meio ISP-4 apresentou apenas $1,3 \times 10^{5} \mathrm{UFC} / \mathrm{ml}$. Com isso, é possível observar similaridade aos resultados obtidos na pesquisa realizada por Rahman et al. (2011) sobre actinobactérias isoladas de solo, onde foi observado que o número máximo de colônias isoladas por diluição seriada a partir de $100 \mathrm{mg} / \mathrm{ml}$ de solo foi de $1,45 \times 10^{-6} \mathrm{UFC} / \mathrm{g}$ de solo.

\section{Identificação das actinobactérias}

As cepas foram codificadas como "AC", indicando actinobactéria, seguido de "AL" para se referir ao estado de Alagoas + o número da cepa isolada. A Tabela 1 mostra a identificação obtida através da observação de características macro e microscópicas das 22 cepas isoladas.

Tabela 1: Características morfológicas e micromorfológicas das cepas de actinobactérias isoladas do Bokashi.

\begin{tabular}{ccccc}
\hline \multirow{2}{*}{ CEPAS } & \multicolumn{2}{c}{ Macromorfologia } & \multicolumn{2}{c}{ Micromorfologia } \\
\cline { 2 - 5 } AC-AL-01 & Coloração & Morfologia & Micélio & $\begin{array}{c}\text { Estruturas } \\
\text { microscópicas }\end{array}$ \\
& & $\begin{array}{l}\text { Formas } \\
\text { filamentosas }\end{array}$ & $\begin{array}{l}\text { Aéreo e ramificado } \\
\text { sob o substrato }\end{array}$ & $\begin{array}{c}\text { Esporos em cadeias de } \\
\text { espirais }\end{array}$
\end{tabular}




\section{ACTINOBACTERIA WITH AGRICULTURAL BIOTECHNOLOGICAL POTENTIAL ISOLATED FROM FERMENTED} ORGANIC FERTILIZER (BOKASHI)

SANTOS, Leonardo da Silva; SOUZA, Giselle Silva de; SILVA, Luana Gomes da; ARAÚJO, Lyslem Riquelem de; SILVA, Mirca Melo Rodrigues da; LOPES, Esmeralda Aparecida Porto

\begin{tabular}{|c|c|c|c|c|}
\hline AC-AL-02 & Verde oliva & $\begin{array}{l}\text { Formas } \\
\text { filamentosas }\end{array}$ & $\begin{array}{l}\text { Aéreo e ramificado } \\
\text { sob o substrato }\end{array}$ & $\begin{array}{l}\text { Hifas ramificadas e cadeias } \\
\text { de esporos em biverticilos } \\
\text { espirais }\end{array}$ \\
\hline AC-AL-03 & Cinza & Bastonetes & $\begin{array}{l}\text { Apenas ramificado } \\
\text { sobre o substrato }\end{array}$ & $\begin{array}{l}\text { Fragmentação em formatos } \\
\text { bacilares e esféricos }\end{array}$ \\
\hline AC-AL-04 & Vermelha & Cocos & $\begin{array}{l}\text { Apenas ramificado } \\
\text { sobre o substrato }\end{array}$ & $\begin{array}{l}\text { Formas filamentosas e } \\
\text { presença de cocos }\end{array}$ \\
\hline AC-AL-05 & Amarela & $\begin{array}{l}\text { Emaranhado de } \\
\text { bacilos e } \\
\text { cocobacilos }\end{array}$ & $\begin{array}{l}\text { Apenas ramificado } \\
\text { sobre o substrato }\end{array}$ & $\begin{array}{l}\text { Fragmentação em formatos } \\
\text { bacilares e esféricos }\end{array}$ \\
\hline AC-AL-06 & Creme & Cocos soltos & $\begin{array}{l}\text { Apenas ramificado } \\
\text { sobre o substrato }\end{array}$ & $\begin{array}{l}\text { Fragmentação em formatos } \\
\text { bacilares e esféricos }\end{array}$ \\
\hline AC-AL-07 & Branca & $\begin{array}{l}\text { Forma } \\
\text { filamentosa }\end{array}$ & $\begin{array}{l}\text { Apenas ramificado } \\
\text { sobre o substrato }\end{array}$ & $\begin{array}{l}\text { Fragmentação em formatos } \\
\text { bacilares e esféricos }\end{array}$ \\
\hline AC-AL-08 & Branca & $\begin{array}{l}\text { Presença de } \\
\text { bacilos e } \\
\text { cocobacilos }\end{array}$ & $\begin{array}{l}\text { Apenas ramificado } \\
\text { sobre o substrato }\end{array}$ & $\begin{array}{l}\text { Fragmentação em formatos } \\
\text { bacilares e esféricos }\end{array}$ \\
\hline AC-AL-09 & Laranja & Cocos soltos & $\begin{array}{l}\text { Apenas ramificado } \\
\text { sobre o substrato }\end{array}$ & $\begin{array}{l}\text { Fragmentação em formatos } \\
\text { bacilares e esféricos }\end{array}$ \\
\hline AC-AL-10 & Branca & Cocos soltos & $\begin{array}{l}\text { Aéreo e ramificado } \\
\text { sob o substrato }\end{array}$ & Esporos únicos \\
\hline AC-AL-11 & Amarela & Cocos soltos & $\begin{array}{l}\text { Apenas ramificado } \\
\text { sobre o substrato }\end{array}$ & $\begin{array}{l}\text { Hifas ramificadas e cadeias } \\
\text { de esporos em biverticilos } \\
\text { espirais }\end{array}$ \\
\hline AC-AL-12 & Branca & $\begin{array}{l}\text { Bacilos e } \\
\text { cocobacilos }\end{array}$ & $\begin{array}{l}\text { Ausência de micélio } \\
\text { aéreo }\end{array}$ & $\begin{array}{l}\text { Fragmentação em formatos } \\
\text { bacilares e esféricos }\end{array}$ \\
\hline AC-AL-13 & Branca & $\begin{array}{l}\text { Cocos e } \\
\text { cocobacilos }\end{array}$ & $\begin{array}{l}\text { Apenas ramificado } \\
\text { sobre o substrato }\end{array}$ & $\begin{array}{l}\text { Fragmentação em formatos } \\
\text { bacilares e esféricos }\end{array}$ \\
\hline AC-AL-14 & Amarela & $\begin{array}{l}\text { Cocos e } \\
\text { cocobacilos }\end{array}$ & $\begin{array}{l}\text { Apenas ramificado } \\
\text { sobre o substrato }\end{array}$ & $\begin{array}{l}\text { Fragmentação em formatos } \\
\text { bacilares e esféricos }\end{array}$ \\
\hline AC-AL-15 & Amarela & $\begin{array}{l}\text { Forma } \\
\text { filamentosa }\end{array}$ & $\begin{array}{l}\text { Apenas ramificado } \\
\text { sobre o substrato }\end{array}$ & $\begin{array}{l}\text { Fragmentação em formatos } \\
\text { bacilares e esféricos }\end{array}$ \\
\hline AC-AL-16 & Branca & $\begin{array}{l}\text { Forma } \\
\text { filamentosa }\end{array}$ & $\begin{array}{l}\text { Apenas ramificado } \\
\text { sobre o substrato }\end{array}$ & $\begin{array}{l}\text { Fragmentação em formatos } \\
\text { bacilares e esféricos }\end{array}$ \\
\hline AC-AL-17 & $\begin{array}{l}\text { Creme com } \\
\text { bordas } \\
\text { brancas }\end{array}$ & $\begin{array}{l}\text { Cocobacilos. } \\
\text { Presença de } \\
\text { finos filamentos }\end{array}$ & $\begin{array}{l}\text { Apenas ramificado } \\
\text { sobre o substrato }\end{array}$ & $\begin{array}{l}\text { Hifas ramificadas e } \\
\text { fragmentação em formas } \\
\text { bacilares e esféricas }\end{array}$ \\
\hline AC-AL-18 & Branca & $\begin{array}{l}\text { Forma } \\
\text { filamentosa }\end{array}$ & $\begin{array}{l}\text { Aéreo e ramificado } \\
\text { sob o substrato }\end{array}$ & $\begin{array}{l}\text { Hifas ramificadas e } \\
\text { onduladas }\end{array}$ \\
\hline AC-AL-19 & Amarela & $\begin{array}{l}\text { Forma bacilar e } \\
\text { esférica. } \\
\text { Presença de } \\
\text { finos filamentos }\end{array}$ & $\begin{array}{l}\text { Apenas ramificado } \\
\text { sobre o substrato }\end{array}$ & $\begin{array}{l}\text { Hifas ramificadas e cadeias } \\
\text { de esporos em } \\
\text { fragmentações bacilares e } \\
\text { espirais }\end{array}$ \\
\hline AC-AL-2O & Marrom & $\begin{array}{l}\text { Cocos soltos e } \\
\text { presença de } \\
\text { bacilos e } \\
\text { cocobacilos }\end{array}$ & $\begin{array}{l}\text { Apenas ramificado } \\
\text { sobre o substrato }\end{array}$ & $\begin{array}{l}\text { Fragmentação em formatos } \\
\text { bacilares e esféricos }\end{array}$ \\
\hline AC-AL-2 1 & Branca & $\begin{array}{l}\text { Cocos e } \\
\text { cocobacilos }\end{array}$ & $\begin{array}{l}\text { Aéreo e ramificado } \\
\text { sob o substrato }\end{array}$ & $\begin{array}{l}\text { Emaranhado de hifas, } \\
\text { filamentos com cocos nas } \\
\text { extremidades }\end{array}$ \\
\hline AC-AL-22 & Branca & $\begin{array}{l}\text { Cocos soltos e } \\
\text { presença de } \\
\text { bacilos e } \\
\text { cocobacilos }\end{array}$ & $\begin{array}{l}\text { Apenas ramificado } \\
\text { sobre o substrato }\end{array}$ & $\begin{array}{l}\text { Formas filamentosas e } \\
\text { presença de cocos }\end{array}$ \\
\hline
\end{tabular}

AC-AL $=$ Actinobactéria + Alagoas $+\mathrm{N}^{\circ}$ da cepa.

Fonte: Dados da Pesquisa (2021). 


\section{ACTINOBACTERIA WITH AGRICULTURAL BIOTECHNOLOGICAL POTENTIAL ISOLATED FROM FERMENTED} ORGANIC FERTILIZER (BOKASHI)

SANTOS, Leonardo da Silva; SOUZA, Giselle Silva de; SILVA, Luana Gomes da; ARAÚJO, Lyslem Riquelem de; SILVA, Mirca Melo Rodrigues da; LOPES, Esmeralda Aparecida Porto

Após a observação de tais características morfológicas estruturais a nível macro e microscópico presentes nas cepas obtidas, foram consideradas para a caracterização das cepas a nível de gênero (Tabela 2).

Tabela 2: Identificação a nível de gêneros das prováveis actinobactérias isoladas do Bokashi.

\begin{tabular}{|c|c|c|}
\hline CEPAS & $\begin{array}{c}\text { Características morfológicas e } \\
\text { micromorfológicas }\end{array}$ & $\begin{array}{l}\text { Prováveis gêneros } \\
\text { (Willams et al., 1989) }\end{array}$ \\
\hline $\begin{array}{l}\text { AC-AL-01 } \\
\text { AC-AL-02 } \\
\text { AC-AL-O4 } \\
\text { AC-AL-O5 } \\
\text { AC-AL-1 } 1 \\
\text { AC-AL-18 } \\
\text { AC-AL-19 } \\
\text { AC-AL-22 }\end{array}$ & $\begin{array}{l}\text { Forma filamentosa, com micélio aéreo ou } \\
\text { ramificado sob ou sobre o substrato com } \\
\text { esporos e cadeias em espiarias, podendo } \\
\text { apresentar hifas ramificadas ou onduladas } \\
\text { com cadeias de esporos que podem } \\
\text { apresentar formas bacilares e/ou esféricas } \\
\text { nas extremidades }\end{array}$ & Streptomyces \\
\hline $\begin{array}{l}\text { AC-AL-03 } \\
\text { AC-AL-06 } \\
\text { AC-AL-07 } \\
\text { AC-AL-08 } \\
\text { AC-AL-09 } \\
\text { AC-AL-12 } \\
\text { AC-AL-13 } \\
\text { AC-AL-14 } \\
\text { AC-AL-15 } \\
\text { AC-AL-16 }\end{array}$ & $\begin{array}{l}\text { Presença de bacilos, com ramificação } \\
\text { apenas sob o substrato com fragmentação } \\
\text { em formas bacilares ou esféricas, podendo } \\
\text { também apresentar forma filamentosa e } \\
\text { bacilares com ramificações apenas sob o } \\
\text { substrato também fragmentando-se em } \\
\text { formas bacilares e esféricas }\end{array}$ & Nocardia \\
\hline $\begin{array}{l}\text { AC-AL-17 } \\
\text { AC-AL-2O }\end{array}$ & $\begin{array}{l}\text { Cocobacilos com a presença de finos } \\
\text { filamentos com micélio apenas ramificado } \\
\text { sob o substrato, com hifas ramificadas e } \\
\text { fragmentação em formas bacilares e } \\
\text { esféricas, também podendo apresentar } \\
\text { foma apresentando-se em cocos soltos e } \\
\text { presença de bacilos e cocobacilos, com } \\
\text { micélio ramificado sobre o substrato, } \\
\text { fragmentação em formatos bacilares e } \\
\text { esféricas }\end{array}$ & Terrabacter \\
\hline AC-AL-10 & $\begin{array}{l}\text { Cocos soltos com micélio aéreo } \\
\text { eramificado sob o substrato e com } \\
\text { apresença de esporos únicos }\end{array}$ & Micromonospora \\
\hline AC-AL-2 1 & $\begin{array}{l}\text { Cocos e cocobacilos com micélio aéreo e } \\
\text { ramificado sob o substrato com a presença } \\
\text { de emaranhado de hifas, filamentos com } \\
\text { cocos nas extremidades }\end{array}$ & Mycobacterium \\
\hline
\end{tabular}

AC-AL $=$ Actinobactéria + Alagoas $+\mathrm{N}^{\circ}$ da cepa

Fonte: Dados da pesquisa (2021).

Williams et al. (1989) ainda ressaltam que as actinobactérias são microrganismos Gram-positivos, característica identificada em todas as cepas obtidas. Assim, foi possível 
SANTOS, Leonardo da Silva; SOUZA, Giselle Silva de; SILVA, Luana Gomes da; ARAÚJO, Lyslem Riquelem de; SILVA, Mirca Melo Rodrigues da; LOPES, Esmeralda Aparecida Porto

identificar os gêneros aos quais as actinobactérias pertencem, como sendo: $45,45 \%$ Nocardia; 36,36\% Streptomyces; 9,10\% Terrabacter; 4,54\% Micromonospora; e 4,54\% Mycobacterium (Figura 4). Diferindo-se dos resultados de Santos et al. (2019), que obtiveram o gênero Streptomyces com maior predominância em três áreas de estudo.

Figura 4: Percentual dos prováveis gêneros das cepas de actinobactéria identificadas a partir do isolamento do Bokashi.

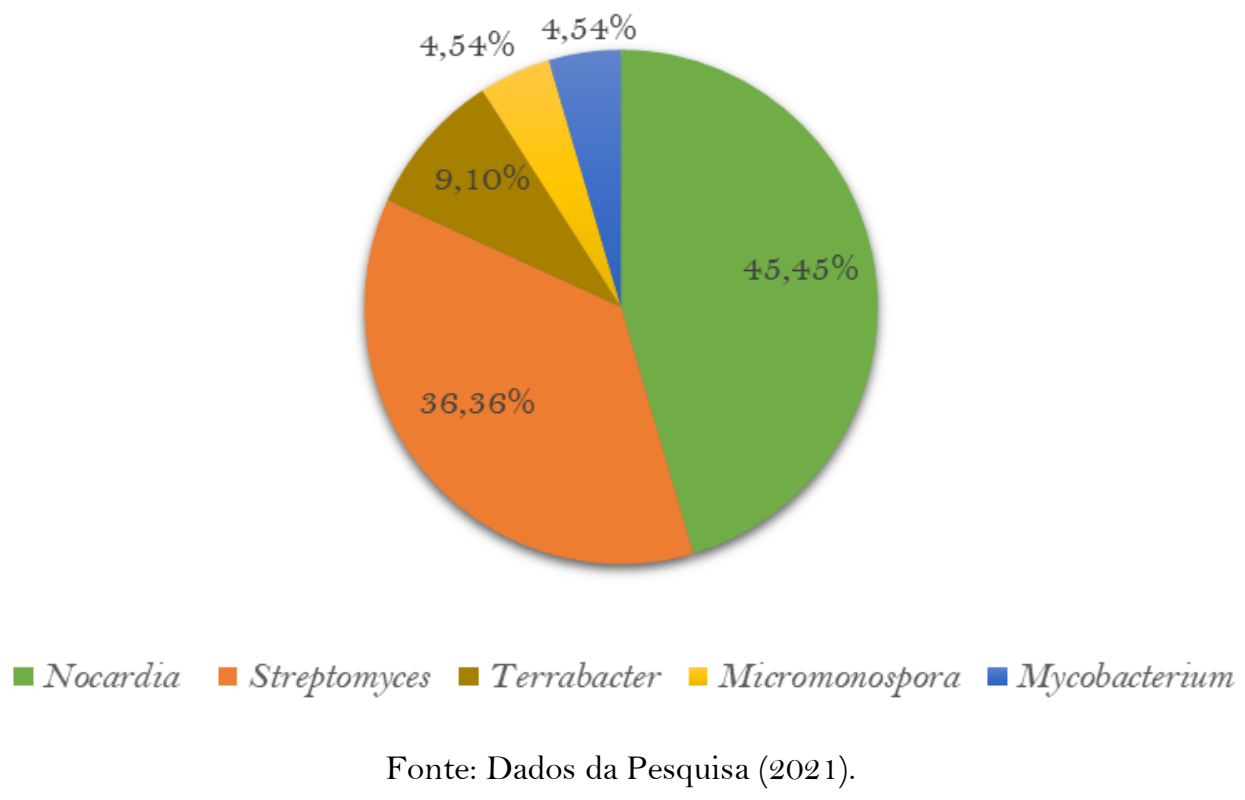

Com isso, os resultados obtidos nesta identificação mostraram-se similares aos do estudo realizado por Lacey (1997), que obteve predominância dos gêneros Nocardia e Streptomyces, de actinobactérias isolados de processo de compostagem. Já no trabalho desenvolvido por Santos et al. (2019), o gênero Nocardia foi identificado em apenas 13\% das 24 cepas analisadas de actinobactérias isoladas em áreas suscetíveis à desertificação, assim como o gênero Mycobacterium.

Os gêneros que compõem o filo Actinobacteria apresentam enorme diversidade em termos de sua morfologia, fisiologia e capacidades metabólicas (CHOI et al., 2016). No Brasil, o gênero Streptomyces é frequentemente o mais isolado com os meios padrões utilizados para o isolamento de actinobactérias (SEMÊDO et al., 2001), seguido do gênero Nocardia. Entre eles, o gênero Streptomyces recebe maior destaque devido a sua grande capacidade para biossíntese de moléculas bioativas e biodegradação de compostos 
orgânicos, estando algumas espécies associadas no processo de fixação biológica de nitrogênio no solo e outras na produção de fitohormônios importantes para o crescimento e proteção das plantas contra fitopatógenos (SADEGHI et al., 2012).

Apesar de várias espécies do gênero Nocardia serem classificadas como microrganismos patogênicos, algumas outras são de vida livre e podem ser encontradas no solo ou em condições ambientais adversas (MIKAMI, 2007; MANDELL; BENNETT; DOLIN, 2010). Por existirem nessa variedade de ambientes, esses microrganismos podem produzir moléculas bioativas com estruturas químicas únicas, podendo degradar substâncias tóxicas e se transformar em substâncias úteis para usos industriais (LUO et al., 2010; LUO; HIESSL; STEINBÜCHEL; 2014; DHAKAL et al., 2016).

Assim, esses microrganismos também apresentam potencial biotecnológico que pode ser aplicado na biorremediação de solos, principalmente em solos afetados por produtos químicos sintéticos comumente utilizados na agricultura, como descrito na pesquisa de Giardina, Giardi e Filacchioni (1980) sobre um novo metabólito envolvido na degradação de atrazina, composto presente em herbicidas utilizados em cultuas de milho, cana-de-açúcar e sorgo para controlar ervas daninhas, por uma bactéria isolada do solo pertencente ao gênero Nocardia. Pode-se citar também pesquisas como as de Bekhi e Khan (1986), Bekhi et al. (1993) e Tomassoni et al. (2014) sobre outras técnicas de biorremediação de solos. Martinez, Silva e Fay (2007) conseguiram identificar uma espécie também do gênero Nocardia envolvidas na degradação de sulfentrazona, um herbicida bastante utilizado em diversas culturas vegetais no Brasil.

Há também diversas pesquisas que mostram a eficácia da utilização de actinobactérias no controle biológico de fungos fitopatogênicos, destacando-se o gênero Streptomyces como o mais estudado devido à sua produção de antibióticos e ao seu efeito como agentes biológicos potenciais no controle de doenças fúngicas (BRESSAN; FIGUEIREDO, 2003). Comprovando isto, pode-se destacar algumas espécies de Streptomyces que foram usadas em Pythium aphanidermatum, causador da podridão nas raízes das plantas, provocando o tombamento das mesmas (PINTO et al., 2010; TEIXEIRA et al., 2013), em Phytopthora sp. causador da podridão radicular na pimenta (EZZIYYANI et al., 2007), em Rhizoctonia solani e Pseudomonas solanacearum em tomate 
SANTOS, Leonardo da Silva; SOUZA, Giselle Silva de; SILVA, Luana Gomes da; ARAÚJO, Lyslem Riquelem de; SILVA, Mirca Melo Rodrigues da; LOPES, Esmeralda Aparecida Porto

(PATIL et al., 2011) e entre outros microrganismos fitopatogênicos comuns na agricultura.

\section{CONCLUSÃO}

Foram isoladas e identificadas 22 cepas de actinobactérias, das quais 77,27\% foram provenientes do meio AY*; $13,64 \%$ do meio ISP-4 e 9,09\% do meio MC. A identificação dos gêneros mostrou que as cepas estavam distribuídas entre: 45,45\% Nocardia; 36,36\% Streptomyces; 9,10\% Terrabacter; 4,54\% Micromonospora; e 4,54\% Mycobacterium.

Tendo em vista que a sociedade atual busca estratégias que permitam o aumento da produção de alimentos sem o prejuízo ao meio ambiente e a saúde humana e do planeta, os resultados obtidos no presente estudo enfatizam a necessidade de aplicação de diferentes testes biotecnológicos utilizando o grupo das actinobactérias como um recurso alternativo para que viabilize uma produção agrícola mais sustentável e menos nociva.

\section{AGRADECIMENTOS}

O presente trabalho foi desenvolvido com o apoio da Fundação de Amparo à Pesquisa do Estado de Alagoas (FAPEAL).

\section{REFERENCIAS}

1. ALBUQUERQUE, Ricardo de; ITO, Nair Massako Kotayama; MIYAJI, Claudio Issamu. Comparative study of different culture media for salmonella recovery in feedstuffs and feeds. Brazilian Journal of Veterinary Research and Animal Science, v. 37, n. 1, p. 16-31, 2000. 
2. BEHKI, R. M.; KHAN, S. U. Degradation of atrazine by Pseudomonas: Ndealkylation and dehalogenation of atrazine and its metabolites. Journal of Agricultural and Food Chemistry, Easton, v. 34, p. 746-749, 1986.

3. BEHKI, R. M.; TOPP, E.; DICK, W.; GERMON, P. Degradation of atrazine, propazine, and simazine by Rhodococcus strain B-30. Journal of Agricultural and Food Chemistry, Easton, v. 42, p. 1237-1241, 1993.

4. BONFIM, Filipe Pereira Giardini; HONÓRIO, Isabela Cristina Gomes; REIS, Iná Lima; PEREIRA, Adalgisa de Jesus; SOUZA, Daniela Boanares de. Caderno dos microrganismos eficientes (EM): instruções práticas sobre o uso ecológico e social do EM. Departamento de Fitotecnia Campus da Universidade Federal de Viçosa, Viçosa, 2011.

5. BRESSAN, W.; FIGUEIREDO, J. E. F. Controle biológico de raças e isolados de Colletotrichum graminicola, do sorgo, por Actinomicetos. Embrapa Milho e Sorgo-Comunicado Técnico (INFOTECA-E), 2003.

6. CALVO, Pamela; NELSON, Louise; KLOEPPER, Joseph W. Agricultural uses of plant biostimulants. Plant and soil, v. 383, n. 1-2, p. 3-41, 2014.

7. CHOI, J. et al. Report on 31 unrecorded bacterial species in Korea that belong to the phylum Actinobacteria. Journal of Species Research, v. 5, n. 1, p. 1-13, 2016.

8. COOK, R. James; BAKER, Kenneth Frank. The nature and practice of biological control of plant pathogens. St. Paul, The American Phytopathology Society, 1983. 539p.

9. CPRM - Serviço Geológico do Brasil. Projeto cadastro de fontes de abastecimento por água subterrânea: Diagnóstico do município de Junqueiro, estado de Alagoas. Disponível em: https://rigeo.cprm.gov.br/jspui/bitstream/doc/15277/1/rel_cadastros_junquei ro.pdf. Último acesso em: 30 de mai. 2021.

10. DHAKAL, Dipesh et al. Genetic manipulation of Nocardia species. Current protocols in microbiology, v. 40, n. 1, p. 10F. 2.1-10F. 2.18, 2016. Disponível em: https://doi.org/10.1002/9780471729259.mc10fo2s40.

11. DEMAIN, Arnold L. Why do microorganisms produce antimicrobials? In: HUNTER, P.A.; DARBY, G. K.; RUSSELL, N. J. (Org.). Fifty Years of 
Antimicrobials: Past, Prospective and Future Trends. Cambridge: University Press, p. 205-228, 1995.

12. EZZIYYANI, M,; REQUENA, M. E.; EGEA-GILABERT, C.; CANDELA, M.

E. Biological control of Phytophthora root rot of pepper using Trichoderma harzianum and Streptomyces rochei in combination. Phytopathology, v. 155, p. 342-349, 2007.

\section{FRANCO, D. C. Z. Atividade antifúngica do óleo resina de Copaifera} langsdorffii Desf. frente a espécies de fungos dermatófitos. 2012. Dissertação (Pós-Graduação em Ciências Farmacêuticas) - Universidade Federal de Juiz de Fora, Juiz de Fora, 2012.

14. GONZÁLEZ, Ignacio; AYUSO-SACIDO, Angel; ANDERSON, Annaliesa; GENILLOUD, Olga. Actinomycetes isolated from lichens: Evaluation of their diversity and detection of biosynthetic gene sequences. FEMS Microbiology Ecology, v.54, p.401-415, 2005.

15. GIARDINA, M. C.; GIARDI, M. T.; FILACCHIONI, G. 4-Amino-2-chloro-1, 3, 5-triazine: a new metabolite of atrazine by a soil bacterium. Agricultural and Biological Chemistry, v. 44, n. 9, p. 2067-2072, 1980.

16. Instituto Brasileiro de Geografia e Estatística. Junqueiro, Alagoas. Disponível em: https://cidades.ibge.gov.br/brasil/al/junqueiro/panorama. Último acesso em: 30 de mai. 2021.

17. Instituto do Meio Ambiente do Estado de Alagoas. Reserva Madeira. Disponível em: http://www.ima.al.gov.br/reserva-particular-do-patrimonionatural-rppn/relacao-das-rppn-estaduais/reserva-madeiras/. Último Acesso em: 30 de mai. 2021.

18. KUMAR, Baduru Lakshman; GOPAL, DVR Sai. Papel efetivo dos microrganismos indígenas para o ambiente sustentável. 3 Biotech, v. 5, n. 6, p. $867-876,2015$.

19. KURTBOKE, D. I.; SWINGS, Jean. Microbial genetic resources and Biodiscovery. Microbial Genetic Resources and Biodiscovery, 2004.

20. LACEY, J. Actinomycetes in composts. Koge, v. 4, p. 113-126, 1997.

21. LUO, Q. et al. Insights into the microbial degradation of rubber and guttapercha by analysis of the complete genome of Nocardia nova SH 22a. Applied 
and environmental microbiology, v. 80, n. 13, p. 3895-3907, 2014. Disponível em: https://doi.org/10.1128/AEM.00473-14.

22. LUO, Q.; HIESSL, S.; STEINBÜCHEL, A. Functional diversity of Nocardia in metabolism. Environmental microbiology, v. 16, n. 1, p. 29-48, 2014. Disponível em: https://doi.org/10.1111/1462-2920.12221.

23. MANDELL G. L.; BENNETT J. E.; DOLIN R. M. D. and BENNETT'S principles and pratice of Infectious Diseases. 7th ed. Churchill Livingstone Elsevier, Philadelphia, PA, 2010.

24. MARTINEZ, C. O.; SILVA, CMM de S.; FAY, E. F. Caracterização de bactérias e fungos envolvidos na degradação de sulfentrazona em solos. In: Embrapa Meio Ambiente-Artigo em anais de congresso (ALICE). In: CONGRESO VIRTUAL IBEROAMERICANO SOBRE GESTIÓN DE CALIDAD EN LABORATORIOS, 4., 2007, Barcelona. Resúmenes... Barcelona: Ministerio de Agricultura, Pesca Y Alimentación, 2007. 4 p., 2007.

25. MIKAMI, Y. Biological work on medically important Nocardia species. Actinomycetologica, v. 21, n. 1, p. 46-51, 2007. Disponível em: https://doi.org/10.3209/saj.SAJ2 10107.

26. OCTAVIANO, C. Muito além da tecnologia: os impactos da Revolução Verde.

Com Ciência, n. 120, 2010.

27. PATIL H. J.; SRIVASTAVA, A. K.; SINGH, D. P.; CHAUDHARI, B. L.; ARORA, D. K. Actinomycetes mediated biochemical responses in tomato (Solanum lycopersicum) enhances bioprotection against Rhizoctonia solani. Crop Protection, v.30, p.1269- 1273, 2011.

28. PINTO, Z.V. et al. Podridão das raízes causada por Pythium aphanidermatum, em cultivares de alface produzidas em sistema hidropônico. Summa Phyopatol, v. 37 , n. 4, p. 180-186, 2011.

29. RAHMAN, A.; ISLAM, M. Z.; ISLAM, A. U. Antibacterial Activities of Actinomycete Isolates Collected from Soils of Rajshahi, Bangladesh.

Biotechnology Research International, v. 2011 , p. 1-6, 2011.

30. SADEGHI, A.; KARIMI, E.; DAHAZI, P. A.; JAVID, M. G.; DALVAND, Y.;

ASKARI, H. Plant growth promoting activity of an auxin and siderophore 
producing isolate of Streptomyces under saline soil condition. World Journal of

Microbiology and Biotechnology, v.28, n.4, p. 1503-1509, 2012.

31. SANTOS, F. D.; OLIVEIRA, M. P.; MENESES, A. C. M. A. MARTINS, S. C. S.; MARTINS, C. M. Morfologia de cepas de actinobactérias em áreas suscetíveis à desertificação. Enciclopédia Biosfera, centro científico conhecer, Goiânia, v.16, n.29, p. $1911,2019$.

32. SEMÊDO, L. T. A. S., LINHARES, A. A., GOMES, R. C., MANFIO, G, P., ALVIANO, C. S., LINHARES, L. F. \& COELHO, R. R. R. 2001. Isolation and characterization of actinomycetes from Brazilian tropical soils. Microbiological Research, v. 155, n. 4, p. 291- 299, 2001.

33. SERRANO, J. A.; SANDOVAL, A. H. Manual de laboratorio para el estudio de los actinomicetales patógenos. Venezuela: Universidad de los Andes, 1992.

34. SIQUEIRA, A. P. P.; SIQUEIRA, M. F. B. de. Bokashi: adubo orgânico fermentado. Niterói: Programa Rio Rural, v. 16, 2013.

35. TEIXEIRA, P. L.; SANTOS, S. N.; MELO, I. S. Biodiversidade de actinobactérias do solo da caatinga para controle biológico de pragas. In: Congresso Interinstitucional de Iniciação Científica, 7. 2013, São Paulo. Anais... São Paulo, 2013, p.1-8.

36. TOMASSONI, F.; SANTOS, R. F.; SANTOS, F. S.; CARPINSKI, M; SILVEIRA, L. Técnica de biorremediação do solo. Acta Iguazu, v. 3, n. 3, p. 4656,2014

37. VASCONCELLOS, Rafael Leandro Figueiredo de; SILVA, Mylenne Calciolari Pinheiro da; RIBEIRO, Carlos Marcelo; CARDOSO, Elke Jurandy Bran Nogueira. Isolation and screening for plant growth-promoting (PGP) actinobacteria from Araucaria angustifolia rhizosphere soil. Sci Agric, v.67, n. 6, p.743-6, 2010.

38. WILLIAMS, S. T.; SHARPE, M. E.; HOLT, J. G. Bergey's Manual of Systematic Bacteriology. New York: Williams e Wilkins, v. 4, 1989, 2648 p. 